\title{
A mutant vesicular stomatitis virus with reduced cytotoxicity and enhanced anterograde trans-synaptic efficiency
}

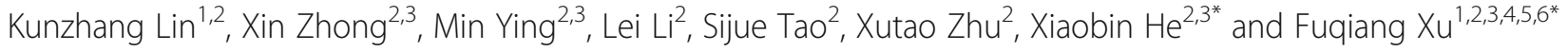

\begin{abstract}
Understanding the connecting structure of brain network is the basis to reveal the principle of the brain function and elucidate the mechanism of brain diseases. Trans-synaptic tracing with neurotropic viruses has become one of the most effective technologies to dissect the neural circuits. Although the retrograde trans-synaptic tracing for analyzing the input neural networks with recombinant rabies and pseudorabies virus has been broadly applied in neuroscience, viral tools for analyzing the output neural networks are still lacking. The recombinant vesicular stomatitis virus (VSV) has been used for the mapping of synaptic outputs. However, several drawbacks, including high neurotoxicity and rapid lethality in experimental animals, hinder its application in long-term studies of the structure and function of neural networks. To overcome these limitations, we generated a recombinant VSV with replication-related $\mathrm{N}$ gene mutation, VSV- $\mathrm{N}_{\text {R7A }}$, and examined its cytotoxicity and efficiency of trans-synaptic spreading. We found that by comparison with the wild-type tracer of VSV, the $N_{R 7 A}$ mutation endowed the virus lower rate of propagation and cytotoxicity in vitro, as well as significantly reduced neural inflammatory responses in vivo and much longer animal survival when it was injected into the nucleus of the mice brain. Besides, the spreading of the attenuated VSV was delayed when injected into the VTA. Importantly, with the reduced toxicity and extended animal survival, the number of brain regions that was trans-synaptically labeled by the mutant VSV was more

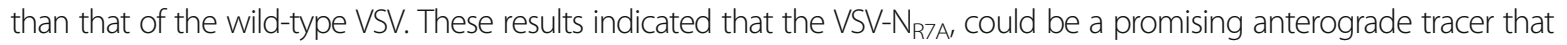
enables researchers to explore more downstream connections of a given brain region, and observe the anatomical structure and the function of the downstream circuits over a longer time window. Our work could provide an improved tool for structural and functional studies of neurocircuit.
\end{abstract}

Keywords: Neurotropic virus, Output network tracing, Vesicular stomatitis virus, Attenuated cytotoxicity, Enhanced anterograde trans-synaptic tracing

\section{Introduction}

Analyzing the connection of brain neural networks, including input and output neural pathways, is the basis of

\footnotetext{
* Correspondence: hexb@wipm.ac.cn; fuqiang.xu@wipm.ac.cn

${ }^{2}$ Center for Brain Science, State Key Laboratory of Magnetic Resonance and Atomic and Molecular Physics, Key Laboratory of Magnetic Resonance in Biological Systems, Wuhan Center for Magnetic Resonance, Wuhan Institute of Physics and Mathematics, Innovation Academy for Precision Measurement Science and Technology, Chinese Academy of Sciences, Wuhan 430071, China

'Wuhan National Laboratory for Optoelectronics, Huazhong University of Science and Technology, Wuhan 430074, China

Full list of author information is available at the end of the article
}

understanding the mechanisms for brain functions and brain diseases $[1,2]$. Trans-synaptic tracing technology based on neurotropic viruses is one of the most effective means to characterize brain neural networks, because viral vectors can be used not only to analyze the structural connections of neural networks, but also to express different genes for functional manipulation [3-11].

Mapping brain connectome requires both retrograde and anterograde trans-synaptic neuronal circuit tracers $[3,12,13]$. In retrograde trans-synaptic labeling system, pseudorabies virus (PRV) as a trans-multi-synaptic tracer, is widely used in

(c) The Author(s). 2020 Open Access This article is licensed under a Creative Commons Attribution 4.0 International License, which permits use, sharing, adaptation, distribution and reproduction in any medium or format, as long as you give appropriate credit to the original author(s) and the source, provide a link to the Creative Commons licence, and indicate if changes were made. The images or other third party material in this article are included in the article's Creative Commons licence, unless indicated otherwise in a credit line to the material. If material is not included in the article's Creative Commons licence and your intended use is not permitted by statutory regulation or exceeds the permitted use, you will need to obtain permission directly from the copyright holder. To view a copy of this licence, visit http://creativecommons.org/licenses/by/4.0/. The Creative Commons Public Domain Dedication waiver (http://creativecommons.org/publicdomain/zero/1.0/) applies to the data made available in this article, unless otherwise stated in a credit line to the data. 
mapping the connection between peripheral-central and central connections $[14,15]$. Rabies virus (RV), a rigorous transmono-synaptic tracer, is broadly used to analyze input brain circuits [4]. Other viral strains or mutants, such as CVS$\mathrm{N} 2 \mathrm{c}^{\Delta \mathrm{G}}$, self-inactivated replication deficient rabies virus (SIRV) and $\mathrm{G} / \mathrm{L}$ gene deletion rabies virus (RV- $\Delta \mathrm{GL})$, which can further reduce toxicity, attain long-term gene manipulation for functional studies $[6,13,16]$. In anterograde trans-synaptic labeling system, herpes simplex virus type 1 (HSV-1) strain 129 (H129) and vesicular stomatitis virus Indiana serotype (VSVInd) are efficient anterograde trans-multi-synaptic tracers for the analysis of output networks [7, 17]. H129, a DNA virus with complex genome, can be used for anterograde multitrans-synaptic pathways from type-specific starter cells [8]. H129- $\Delta$ TK-tdT, with AAV virus complementarily expressing thymidine kinase gene (TK), has been reported for anterograde trans-mono-synaptic tracing to visualize direct projections from a specific neuron type [10]. Vesicular stomatitis virus (VSV) has the advantages of simpler structure, higher expression of exogenous genes and wider infection range [7, 18-20]. Envelope glycoprotein of VSV can be replaced by glycoproteins of other viruses to achieve different labeling characteristics and direction controllable trans-synaptic transfer [21, 22]. But these VSVs have high cytotoxicity that can lead to rapid death of mice, which limits long-term structural observation and gene manipulation or function research, restricting their applications in neuroscience [23]. Several mutants have been obtained by mutating the $\mathrm{N}$ gene related to the replication of VSV [24-27]. After mutating the seventh amino acid of the $\mathrm{N}$ protein $\left(\mathrm{VSV}-\mathrm{N}_{\mathrm{R} 7 \mathrm{~A}}\right.$ ), the replication speed of the virus decreased by $2-3$ orders of magnitude within $24 \mathrm{~h}[24,25]$, which might be used as a better tracer, but whether it still has the ability of anterograde trans-synaptic labeling is still unknown.

Here, we examined the features of VSV- $\mathrm{N}_{\mathrm{R} 7 \mathrm{~A}}$ as an anterograde trans-synaptic tracer. We found that VSV$\mathrm{N}_{\text {R7A }}$ exhibits attenuated cytotoxicity, delayed but more efficient anterograde trans-synaptic capability. We conclude that VSV- $\mathrm{N}_{\mathrm{R} 7 \mathrm{~A}}$ can provide longer time window for neural circuits research, making it a possible new tool for the study of brain output networks.

\section{Materials and methods}

\section{Construction of the recombinant mutant VSV vector}

pVSV-EGFP was bought from Addgene (plasmid \# 36399, Connie Cepko's lab). To construct the mutant VSV $\left(V S V-\mathrm{N}_{\mathrm{R} 7 \mathrm{~A}}\right), \mathrm{N}$ gene with the seventh amino acid mutation ( $R$ to $A$ ) was amplified and inserted into the pVSV-EGFP digested by restriction enzyme MscI and BSTZ17I (New England Biolabs). The sequences of primers designed to amplify $\mathrm{N}$ mutant were: N'(R7A)-F: tggccaTATGAAAAAAACTAACAGTAATCAAAATGTCTGTTACAGTCAAGGCCATC; N'(R7A)-F1: ATCATTGACAACACAGTCATAG; N
'(R7A)-F2: ATGTCTGTTACAGTCAAGGCCATCAT TGACAACACAGTCATAG; N'(R7A)-R: gtatacTCAATGTCATCAGGCTGTCGGGCATT. Plasmids were verified by DNA sequencing.

\section{Rescue and preparation of recombinant VSV}

Rescue of wild-type VSV (WT-VSV) and mutant VSV (Mutant-VSV) is as previously reported [28]. BHK-21 cells with 6-well plate were incubated with vaccinia carrying T7 RNA polymerase for $1 \mathrm{~h}$, then washed with PBS three times, and co-transfected with VSV genome plasmid and packaging plasmids encoding the $\mathrm{N}, \mathrm{P}$ and $\mathrm{L}$ proteins in certain proportions. After $6 \mathrm{~h}$, the supernatant was discarded, and 2 ML Dulbecco's minimum essential media (DMEM) containing 5\% fetal bovine serum (FBS) was added to the 6-well plate and cultured in $31^{\circ} \mathrm{C}, 5 \%(\mathrm{v} / \mathrm{v})$ $\mathrm{CO} 2$ incubator. After $120 \mathrm{~h}$, the supernatant was collected and filtered with $0.1 \mu \mathrm{m}$ filter to infect normal BHK-21 cells. Cells were observed by inverted fluorescence microscopy (Olympus) $24 \mathrm{~h}$ later. The supernatants were collected after complete lesion, filtered with $0.22 \mu \mathrm{m}$ membrane and centrifuged at $50000 \times \mathrm{g}$ for $2.5 \mathrm{~h}$ at $4{ }^{\circ} \mathrm{C}$. The precipitation was suspended with PBS and then concentrated and purified with $20 \%$ sucrose for the second time. The precipitation was suspended with appropriate amount of PBS. The titer was determined by plaque assay and the virus was stored at $-80^{\circ} \mathrm{C}$.

\section{Single-step growth curves of viruses}

Single-step growth curves were carried out at $35^{\circ} \mathrm{C}$ to determine the replication efficiency of the VSVs. BHK-21 cells were grown in twelve-well plates to a density of $70 \% \sim 80 \%$, and infected with each recombinant virus at a multiplicity of infection (MOI) of 3 . After $1 \mathrm{~h}$ of incubation at $35^{\circ} \mathrm{C}$, the viral inoculum was removed, cells were washed 3 times with phosphate buffered saline (PBS), and $1.5 \mathrm{ml}$ of fresh DMEM medium (containing 3\% FBS) was added. Supernatants were harvested at different time points (12, 24, 36, 48, 72 and $96 \mathrm{~h}$ post infection (hpi)), and virus titers were detected by plaque assay.

\section{Virus injection and slices preparation}

In animal experiments, all surgical and experimental procedures were carried out in accordance with the guidelines formulated by the Animal Care and Use Committee of Wuhan Institute of Physics and Mathematics, Chinese Academy of Sciences, and experiments related to VSV were performed in Biosafety Level-2 (BSL2) laboratory. Eight-week-old C57BL/6 mice (20-25 g) were used for VSV injection, and injection process was referred to previous study [29]. $0.1 \mathrm{ul} 5 \times 10^{8} \mathrm{FFU} / \mathrm{ml}$ recombinant VSV was injected into VTA and DG area of dorsal hippocampus. The stereotactic coordinates for DG were: AP: $-2.00 \mathrm{~mm}$; ML: $1.00 \mathrm{~mm}$; DV: $-2.00 \mathrm{~mm}$ 
from the bregma. For VTA were: AP: $-3.20 \mathrm{~mm}$; ML: $0.45 \mathrm{~mm}$; DV: $-4.30 \mathrm{~mm}$ from the bregma. After a certain day, the mice were anesthetized with $5 \%$ chloral hydrate $(600 \mathrm{mg} / \mathrm{kg})$, and perfused with $0.9 \%$ saline and $4 \%$ polyformaldehyde solution respectively. Then, the brains were soaked overnight in $4 \%$ paraformaldehyde solution. After dehydration was completed with $30 \%$ sucrose solution, the brain was sectioned with the thickness of $40 \mu \mathrm{m}$ by frozen section machine. Brain slices were washed 3 times with PBS, 5 min each time. After DAPI staining for $10 \mathrm{~min}$, the brain slices were attached to the microscope slides and sealed with $70 \%$ glycerol.

\section{Immunohistochemistry and fluorescence imaging}

For staining neurons in vivo, the target brain slices were sealed with $10 \%$ sheep serum for $1.5 \mathrm{~h}$, and immunostained with a Cy3-conjugated rabbit antibody against $\mathrm{NeuN}$ (diluted by PBS at 1:300, Merck Millipore, ABN78C3) overnight at $4{ }^{\circ} \mathrm{C}$. For staining microglia cells in vivo, brain slices were blocked with $10 \%$ sheep serum in PBS with $0.3 \%$ Triton X100 for $1.5 \mathrm{~h}$, then incubated with primary antibody (antiIba1: diluted by PBS at 1:1000, LAK4357, WAKO) overnight at $4{ }^{\circ} \mathrm{C}$. After washed 3 times with PBS, slices were incubated with the secondary antibody cy3-conjugated goat anti-rabbit immunoglobulin G (IgG) (1:400, 94,600, Jackson) for $1 \mathrm{~h}$ at $37^{\circ} \mathrm{C}$. All the brain slices above were washed 3 times with PBS, then attached to the microscope slides and sealed with $70 \%$ glycerol. Imaging was performed by using the Olympus VS120 Slide Scanner microscope (Olympus).

\section{Results}

\section{Mutant-VSV can effectively infect neurons in vivo}

Based on the characteristics of rapid amplification, high infection efficiency and expression level of exogenous genes, VSV has been developed into an important gene transfer vector $[7,19]$. It has been previously reported that rearrangement or mutation of viral genes in the genome can reduce the replication speed or toxicity [30-34]. Here, recombinant VSV-N $\mathrm{N}_{\mathrm{R} \text { A }}$ was constructed (Fig. 1). The wild-type and mutant VSV with EGFP reporter were recovered and amplified in BHK21 cells (Fig. 2a). WT-VSV and Mutant-VSV were added to BHK-21 cells at an MOI (multiplicity of infection) of 0.001 . When infected with WT-VSV, obvious fluorescence signals can be detected within $12 \mathrm{~h}$, while Mutant-VSV need $24 \mathrm{~h}$ (Fig. 2b). Obvious cytopathic changes were observed after $48 \mathrm{~h}$ in WT-VSV group, however, cytopathies were observed $72 \mathrm{~h}$ later in VSV-N $\mathrm{N}_{\mathrm{R} 7 \mathrm{~A}}$ group (Fig. 2b). Compared to WT-VSV, Mutant-VSV exhibits a reduction (three orders of magnitude) in virus replication at $35^{\circ} \mathrm{C}$ within $24 \mathrm{hpi}$ (Fig. 2c), which is consistent with previous findings [24]. In addition, the titer of Mutant-VSV increased with time and reached its peak in $72 \mathrm{~h}$, which was one order of magnitude less than that of wild-type VSV (Fig. 2c). The ability of the Mutant-VSV to infect neurons in vivo was investigated. The Mutant-VSV was injected into the DG region of mouse brain. The brain slices were prepared at 1 day post-injection (DPI) and stained with Cy3-conjugated NeuN antibody. Results showed that EGFP fluorescent signals from MutantVSV were co-localized with neurons in vivo (Fig. 2d).

\section{Neuroinflammatory responses induced by the WT-VSV and mutant-VSV vectors}

Viral infections can cause neuroinflammation and induce microglia activation [35, 36]. To evaluate microglial activation induced by WT-VSV and Mutant-VSV infection at the injection site, immunohistochemistry for Iba1, the microglial marker, was performed. Obvious Iba1-positive cells were observed in the WT-VSV group at 1 DPI, but barely in the Mutant-VSV or PBS injected (Mock) DG (Fig. 3a-c). Intense microglial activation was

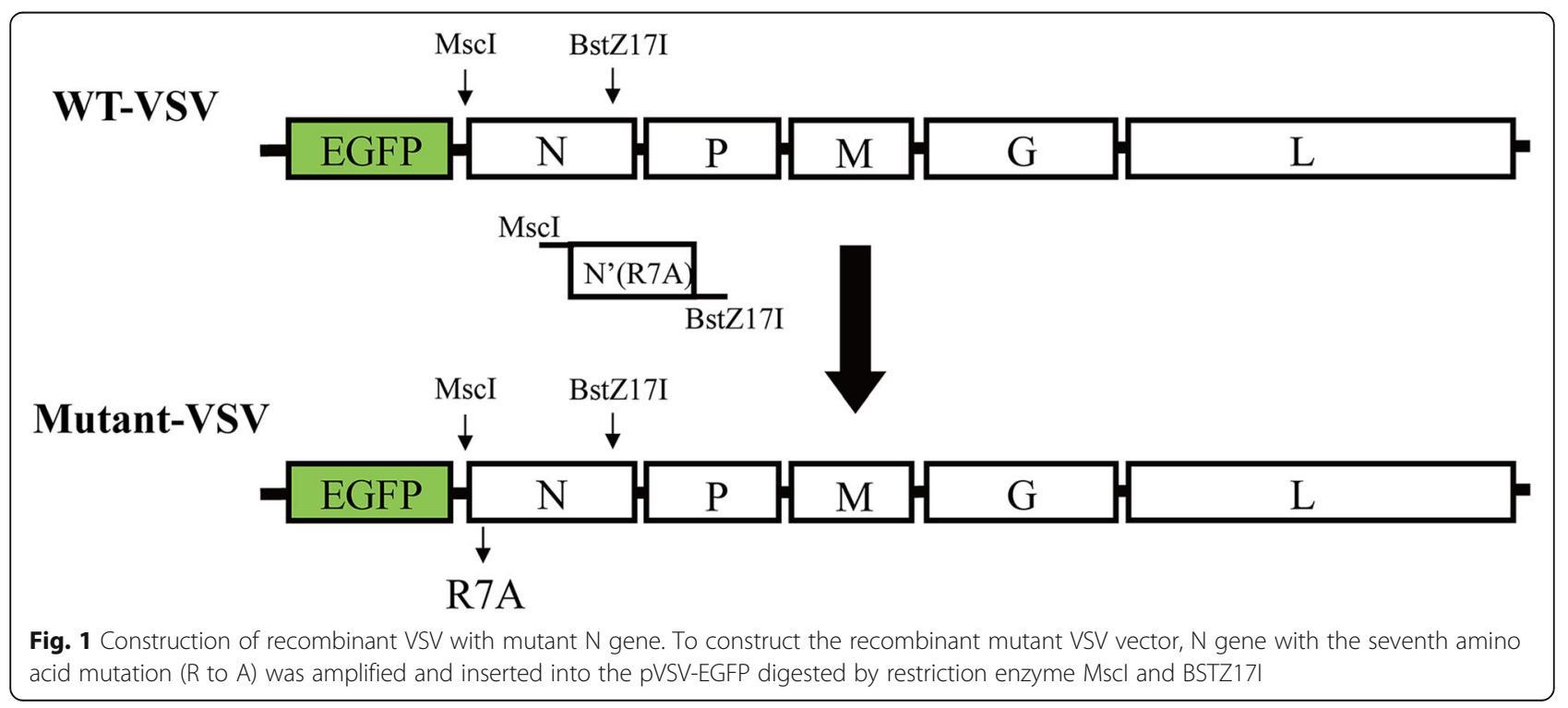




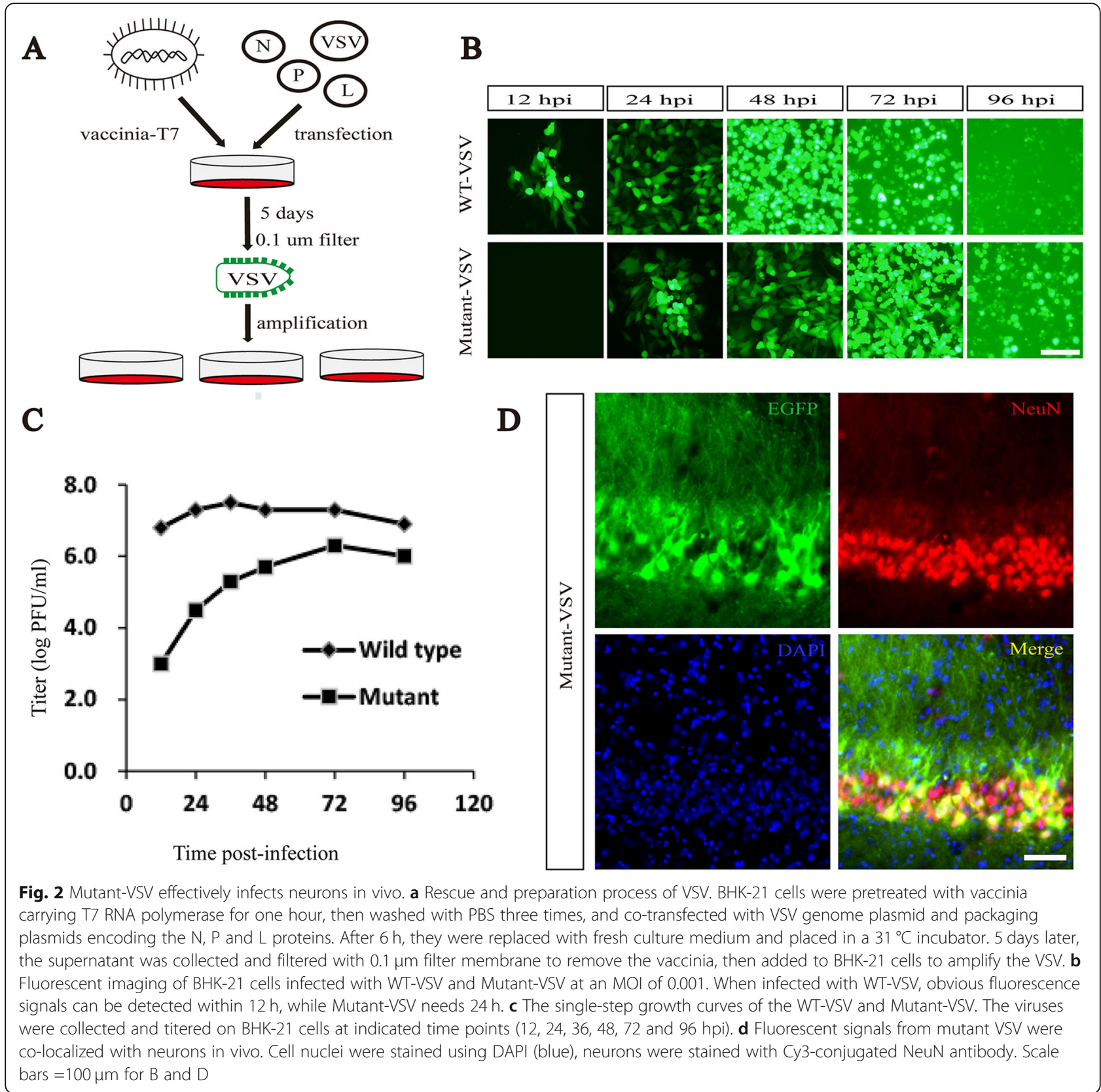

observed at the injection site when WT-VSV or MutantVSV was injected into the DG at 3 DPI, and signals in the WT-VSV group were more than that in the MutantVSV group, while few signals were observed in the PBS injected DG (Fig. 3d-f). By quantification of mean fluorescence intensity (Mean \pm SEM) of Iba1 in DG at 1 DPI (Fig. 3g, Mutant-VSV: $9.251 \pm 0.182$, WT-VSV: $16.02 \pm$ 0.9505, Mock: $8.22 \pm 0.4402$, Mutant-VSV vs Mock: $P=$ 0.0963; WT-VSV vs Mock: $P=0.0017$; WT-VSV vs Mutant-VSV: $P=0.0022$ ) and 3 DPI (Fig. 3h, MutantVSV: $16.29 \pm 0.7438$, WT-VSV: $23.41 \pm 1.836$, Mock: $9.828 \pm 0.7976$, Mutant-VSV vs Mock: $P=0.0041$; WT-
VSV vs Mock: $P=0.0025$; WT-VSV vs Mutant-VSV: $P=0.0229$ ), we found that microglial infiltration was markedly increased at the injection site (DG region) following WT-VSV injection, while microglial activation due to Mutant-VSV infection was significantly milder even after 3 days (Fig. 3). These results indicated that Mutant-VSV was less toxic in the injection site.

\section{Anterograde trans-synaptic labeling with mutant-VSV vector}

VSV has the ability of anterograde trans-synaptic tracing of neural circuits (Fig. 4a), and is used for the output 


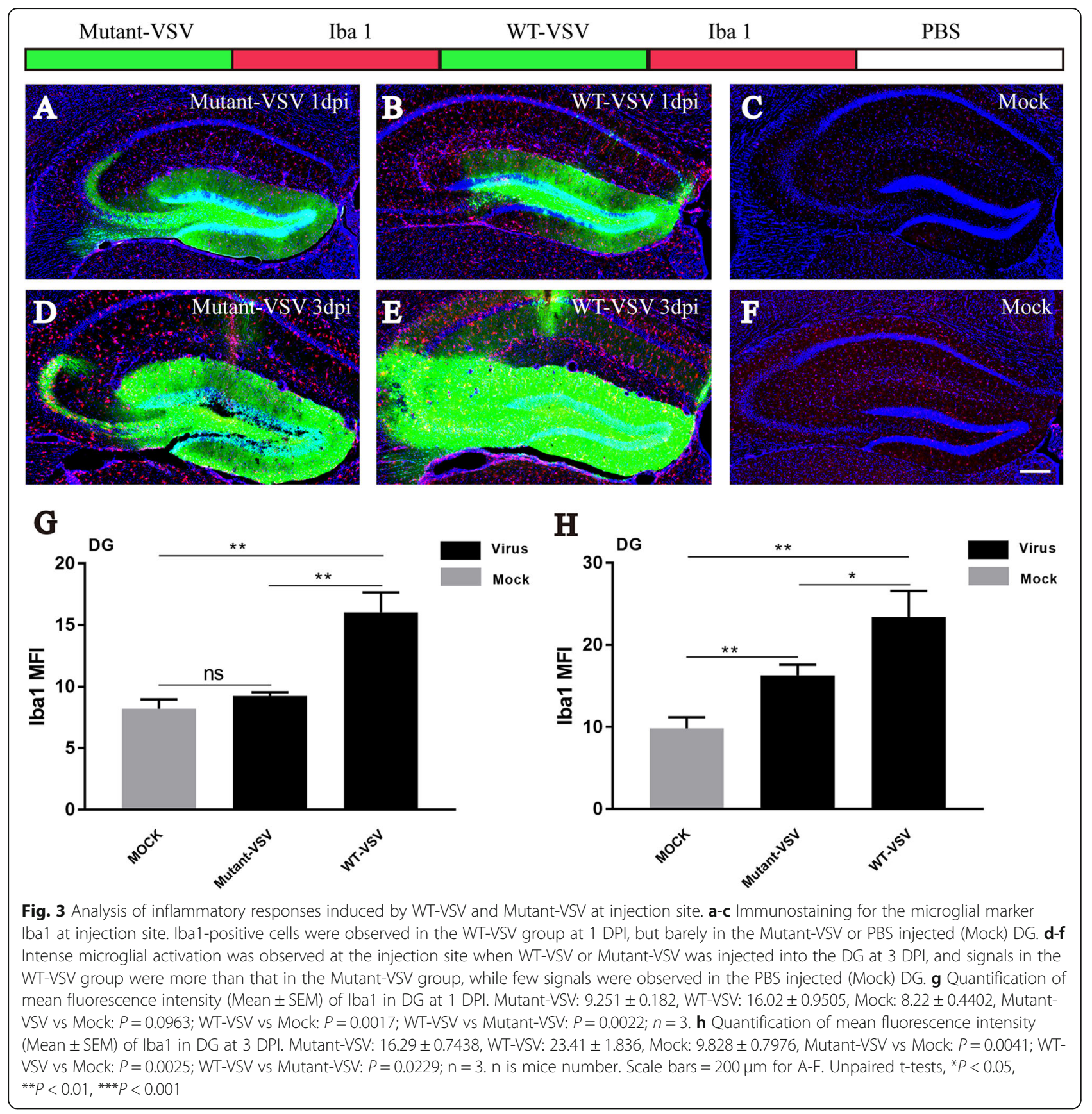

network analysis of specific brain region [37]. Ventral tegmental area (VTA) is an important brain region with complex output neural networks, which performs diverse functions in reward, cognition, motivation, and aversion [38-40]. VTA neurons project to the lateral septal nucleus (LS), the nucleus accumbens (ACB), the caudoputamen $(\mathrm{CP})$, the habenula, the amygdala, the dorsal nucleus raphe (DR), the prefrontal cortex (PFC), the anterior cingulate area (ACA), and the somatomotor areas (MO), among other regions [41-46]. To examine anterograde trans-synaptic ability of Mutant-VSV, the
Mutant-VSV and WT-VSV were injected into the VTA region of mouse brain, and the brain slices were prepared at 3 DPI and 5 DPI. Green signals were observed in injection site (Fig. 4b). Several brain regions including anterior olfactory nucleus (AON), lateral septal nucleus (LS), nucleus accumbens (ACB), bed nuclei of the stria terminalis (BST), habenula, and dorsal nucleus raphe (DR) were labeled by Mutant-VSV at 3 DPI. However, signals were detected in additional brain regions at 5 DPI, including medial preoptic nucleus (MPN), posterior hypothalamic nucleus $(\mathrm{PH})$, dorsomedial nucleus of the 


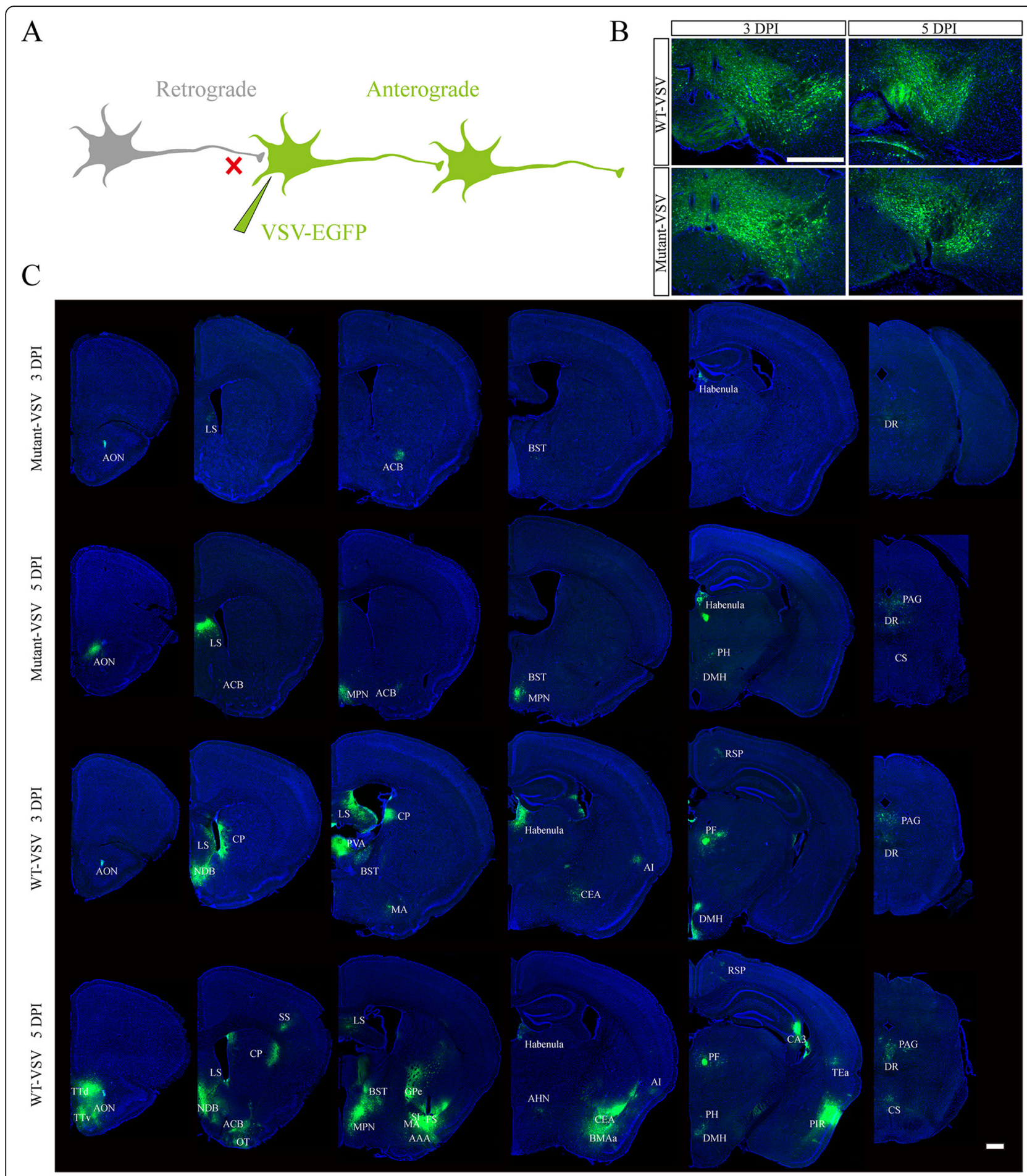

Fig. 4 (See legend on next page.) 
(See figure on previous page.)

Fig. 4 Anterograde trans-synaptic labeling with Mutant-VSV after injection into the VTA. a Schematic of recombinant VSV anterograde transsynaptic labeling. $\mathbf{b}$ The brain slices of injection site at indicated time points (3 DPI and 5 DPI) were imaged. c Anterograde trans-synaptic labeling with Mutant-VSV at indicated time points. Mutant VSV can effectively infect downstream brain area of VTA, and more brain regions were labeled over time, but less brain regions were labeled by Mutant-VSV than by WT-VSV at 5 DPI, which showed that Mutant-VSV had delayed anterograde trans-synaptic ability. The EGFP signal was imaged by using the Olympus VS120 Slide Scanner microscope. Scale bars =500 $\mu \mathrm{m}$ for B and $\mathrm{C}$. The specific name of the brain areas labeled were shown as follows: AON: Anterior olfactory nucleus; TTd: Taenia tecta, dorsal part; TTV: Taenia tecta, ventral part; LS: Lateral septal nucleus; ACB: Nucleus accumbens; NDB: Diagonal band nucleus; OT: Olfactory tubercle; CP: Caudoputamen; SS: Somatosensory areas; MPN: Medial preoptic nucleus; BST: Bed nuclei of the stria terminalis; GPe: Globus pallidus, external segment; SI: Substantia innominata; FS: Fundus of striatum; MA: Magnocellular nucleus; AAA: Anterior amygdalar area; Habenula: Habenula; AHN: Anterior hypothalamic nucleus; CEA: Central amygdalar nucleus; BMAa: Basomedial amygdalar nucleus, anterior part; Al: Agranular insular area; PH: Posterior hypothalamic nucleus; DMH: Dorsomedial nucleus of the hypothalamus; PF: Parafascicular nucleus; RSP: Retrosplenial area; TEa:

Temporal association areas; PIR: Piriform area; CA3: Ammon's horn Field CA3; DR: Dorsal nucleus raphe; PAG: Periaqueductal gray; CS: Superior central nucleus raphe

hypothalamus (DMH), periaqueductal gray (PAG), superior central nucleus raphe (CS) (Fig. 4c). Except for MPN, all of these labelled regions received the direct projection from VTA neurons according to Allen Mouse Brain Connectivity Atlas (http://connectivity.brain-map.org/). These results showed that Mutant-VSV has anterograde trans-synaptic ability, and the trans-synaptic efficiency increases with time. Moreover, Mutant-VSV may anterogradely label the postsynaptic neurons through one synaptic connection at 3 DPI.

Moreover, more brain regions were labeled by wild-type VSV at 3DPI and 5 DPI (Fig. 4c), especially at 5 DPI, including taenia tecta, dorsal part (TTd), diagonal band nucleus (NDB), olfactory tubercle (OT), caudoputamen (CP), somatosensory areas (SS), globus pallidus, external segment (GPe), substantia innominata (SI), fundus of striatum (FS), magnocellular nucleus (MA), anterior amygdalar area (AAA), anterior hypothalamic nucleus (AHN), central amygdalar nucleus (CEA), basomedial amygdalar nucleus, anterior part (BMAa), retrosplenial area (RSP), parafascicular nucleus (PF), ammon's horn Field CA3 (CA3), temporal association areas (TEa), and piriform area (PIR). These results showed that the speed of the anterograde trans-synaptic tracing of Mutant-VSV was slowed down.

\section{Attenuated lethality of mutant-VSV in mice brain compared with WT-VSV}

Rapid lethality in experimental animals is a limitation for most neurotropic viruses in neuroscience applications [47]. It is important to determine the survival time of mice infected with neurotropic virus, because it can provide technical support for virus application in vivo, such as controlling the time window of infection. Eightweek-old C57BL/6 mice were divided into three groups with 10 mice in each. WT-VSV, Mutant-VSV and PBS were injected intracranially into the DG of hippocampus. WT-VSV was rapidly lethal to experimental animals at 3 DPI and more than half of the deaths occurred at 4 DPI, however, in Mutant-VSV group, the first case of death of experimental animals occurred at $11 \mathrm{dpi}$, and time of more than half of the deaths was delayed to 15 DPI (Fig. 5). The survival percentage was analyzed by Logrank test $(P<0.0001$, Fig. 5$)$. These data showed that as compared with WT-VSV, the time of death in MutantVSV infected mice was delayed significantly.

\section{More connected brain networks were labeled with mutant-VSV}

As the rapid death of experimental animals induced by neurotropic virus, the connected brain networks of injection site were not fully resolved. To determine whether the attenuated virus could label more connected network with the extension of survival time, MutantVSV were injected into the VTA of C57BL/6 mice, and the brain slices were imaged at 10 days post-injection. Normal cell morphology of labeled VTA output neurons can be observed at 10 DPI by using Mutant-VSV (Fig. 6a). Moreover, additional labeled brain regions, including prefrontal cortex (PFC), anterior cingulate area (ACA), somatomotor areas (MO), superior colliculus (SC) and superior olivary complex (SOC), were observed with Mutant-VSV at 10 DPI (Fig. 6b), which were not labeled by WT-VSV at 5 DPI (Fig. 4c). More complete comparison of the labeled regions under different conditions were shown in Table 1 . These results suggested that Mutant-VSV could be used to reveal longer range of downstream networks compared with WT-VSV.

\section{Discussion}

Neural network abnormalities can cause many neurological and psychiatric diseases, such as Parkinson's disease, Schizophrenia, Alzheimer's disease and Autism [2]. Analyzing the connection of brain neural networks is the basis of understanding the mechanism of network variation of brain diseases. Neurotropic virus mediated anterograde trans-synaptic tracing is an important approach for mapping the output of brain circuits. Several viral tracers for anterogradely trans-synaptic tracing had been developed [20,48], but the rapid toxicity and lethality to the infected neurons and animals limited their 


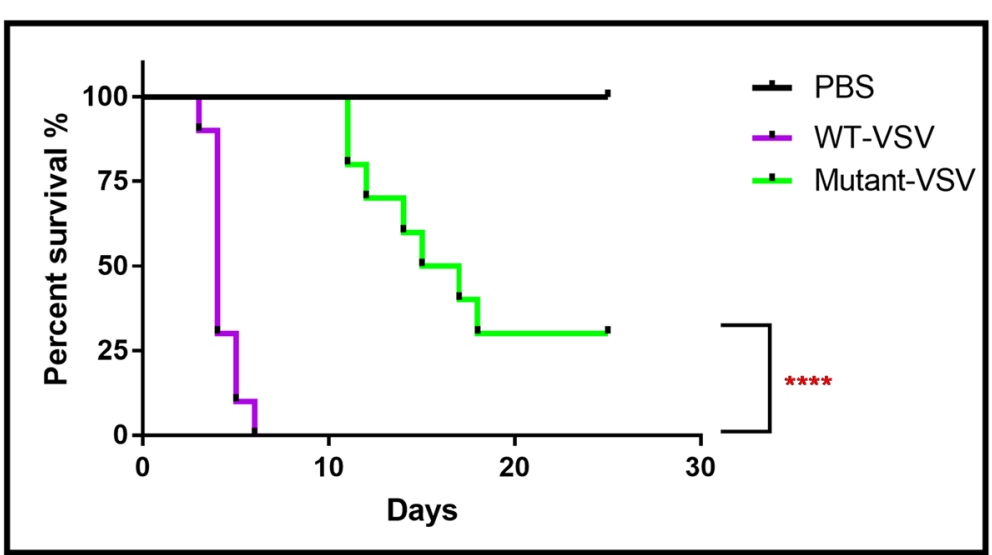

Fig. 5 Survival rate of WT-VSV and Mutant-VSV infected mice. WT-VSV, Mutant-VSV and PBS were injected intracranially into the DG domain of adult mice. WT-VSV was rapidly lethal within 1 week and more than half of all deaths occured at 4 DPI, which occured at 14 DPI in Mutant-VSV group. The percent survival was analyzed by Log-rank test $(n=10$ in each group; $P<0.0001)$. ${ }^{*} P<0.05,{ }^{* *} P<0.01,{ }^{* * *} P<0.001$, ${ }^{* * * *} P<0.0001$

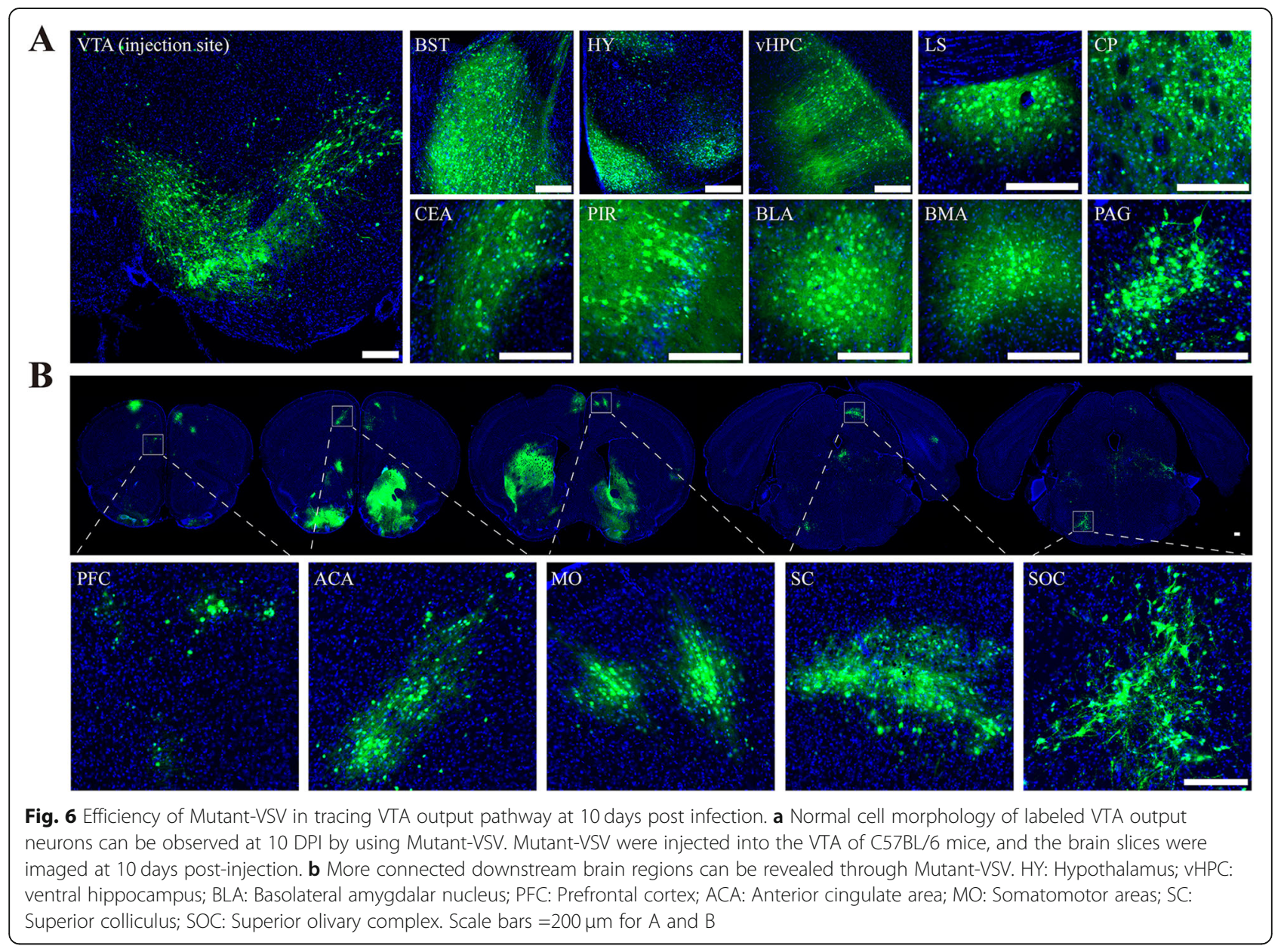


Table 1 Assessment of viral spread from WT-VSV and MutantVSV injections into the VTA

\begin{tabular}{|c|c|c|c|c|c|}
\hline \multirow{2}{*}{$\begin{array}{l}\text { Brain } \\
\text { region }\end{array}$} & \multicolumn{2}{|c|}{ WT-VSV } & \multicolumn{3}{|c|}{ Mutant-VSV } \\
\hline & $3 \mathrm{DPI}$ & $5 \mathrm{DPI}$ & $3 \mathrm{DPI}$ & $5 \mathrm{DPI}$ & $10 \mathrm{DPI}$ \\
\hline $\mathrm{AON}$ & + & ++ & + & ++ & ++ \\
\hline LS & + & ++ & + & ++ & ++ \\
\hline $\mathrm{ACB}(\mathrm{NAC})$ & + & ++ & + & + & ++++ \\
\hline$C P$ & ++ & ++ & - & - & ++++ \\
\hline OT & - & + & - & - & +++ \\
\hline BST & + & ++ & + & + & ++++ \\
\hline Habenula & ++ & +++ & + & ++ & ++ \\
\hline Amygdala & + & ++ & - & - & +++ \\
\hline DR & + & ++ & + & + & ++ \\
\hline PIR & - & ++ & - & - & ++ \\
\hline PFC & - & - & - & - & + \\
\hline ACA & - & - & - & - & ++ \\
\hline $\mathrm{MO}$ & - & - & - & - & ++ \\
\hline SC & - & - & - & - & ++ \\
\hline SOC & - & - & - & - & ++ \\
\hline
\end{tabular}

The absence or presence of labeling was indicated by $(-)$ and (+), respectively. The extent of labeling was indicated with the number of $(+)$. Results showed that with the reduced toxicity and extended animal survival, more connected downstream networks were labeled by the Mutant-VSV compared with the WT-VSV

application in many areas of research that need dissecting the output network according to connection order within a longer time window, which were important to understand not only the anatomical mechanism of the given brain region, but also the variation of the circuits on various neurological and psychiatric disease. In order to overcome these defects, we introduced a replicationrelated mutation within the nucleoprotein, $\mathrm{N}_{\mathrm{R} 7 \mathrm{~A}}$, into the genome of the VSV. We found that compared with the WT-VSV, the $\mathrm{N}_{\mathrm{R} 7 \mathrm{~A}}$ mutation endowed the virus lower rate of propagation and cytotoxicity in vitro, as well as significantly reduced neural inflammatory responses in vivo and much longer animal survival when it was injected into the nucleus of the mice brain. Besides, the Mutant-VSV exhibited effectively anterograde transsynaptic spread in vivo when injected into the VTA, and the order of labeled connection increased with the extension of infection time. Importantly, with the reduced toxicity and extended animal survival, more connected downstream networks were labeled by the Mutant-VSV compared with the WT-VSV.

Viral toxicity is mainly related to viral replication, virulent genes and host immune response [27, 49, 50]. It has been reported that the toxicity of neurotropic viruses can be reduced by decreasing the replication rate $[6,16]$. The $\mathrm{N}$ protein binds to the genomic RNA of VSV to form N-RNA complex, which serves as the template for genomic replication and transcription by the RNA-dependent RNA polymerase [51]. The R7A mutation in $\mathrm{N}$ protein was reported to reduce the genomic replication and transcription at $37^{\circ} \mathrm{C}$ [27]. As expected, by comparison with WT-VSV, Mutant-VSV exhibited a reduction in virus replication and cytotoxicity (Fig. 2 and Fig. 3), which is consistent with previous findings. However, the lower replication rate may affect the expression and trans-synaptic transmission of neurotropic viruses [16]. Therefore, whether it retains the ability of transsynaptic tracing shoud be evaluated. When injected into the VTA region, Mutant-VSV can effectively transmit to the downstream networks at 3 DPI and 5 DPI, although the speed of spreading was slowed down (Fig. 4). Further order of the downstream networks, including prefrontal cortex (PFC), anterior cingulate area (ACA), somatomotor areas (MO), superior colliculus $(\mathrm{SC})$ and superior olivary complex (SOC), were labeled by Mutant-VSV at 10 DPI than that by WT-VSV at 5 DPI, when injected into the VTA of C57BL/6 mice (Fig. 6). Thus, we provide a useful trans-multisynaptic tracer for researchers to dissect downstream neural circuit more efficiently.

With reduced cytotoxicity, the Mutant-VSV makes it possible to deliver optogenetic and calcium indicators to monitor or manipulate the network activity over a longer experimental window. With the canonical anterograde tracer, such as WT-VSV and HSV, the time window that ensures effectively trans-synaptic tracing has been reported to be between 3 and 5 days from the infection [7, 48]. With Mutant-VSV, the useful temporal window for imaging can reach up to $10-15$ days from the infection, which overcoming the shortage of relative short survival time of experimental animals. Meanwhile, VSV is a negative-stranded RNA virus, HSV is a double stranded DNA virus, there are many different characteristics between them, including genome, toxicity and application, etc. [52]. We have provided a more detailed comparison (pros and cons) between VSV- $\mathrm{N}_{\mathrm{R} 7 \mathrm{~A}}$ and the more commonly used HSV variants (H129 and H8). A more detailed comparison was shown in Table 2.

The mutant-VSV, with effective transsynaptic tracing and extended animal survival, also has the potential to achieve time-dependent anterograde trans-synaptic labeling. For example, Mutant-VSV vector that expresses a slow fluorescent timer (sFT), whose fluorescence color changed from blue to red over time, would enable us to differentiate 2nd-order neurons from 1st-order neurons according to the red-to-blue fluorescence intensity ratio [53]. Moreover, Zheng et al. have reported that neural connections can be detected with ex vivo MRI using a ferritin-encoding VSV, but wild-type viral toxicity affects long-term signal acquisition [11]. Therefore, the Mutant-VSV would be an appropriate vector. However, the Mutant-VSV still have some cytotoxicity with the extension of infection time. Future studies are required to 
Table 2 Comparison of viral tracers of anterograde trans-mulisynaptic tracing

\begin{tabular}{|c|c|c|c|c|c|c|c|}
\hline Strain & Genome & Dir & Cell toxicity & Days of survival & Expressing level & Operation risk & Cre/flp dependent \\
\hline WT-VSV & $\begin{array}{l}\text {-ss RNA } \\
12 \mathrm{~kb}\end{array}$ & A & High & $3-5$ & High & Low & $\mathrm{N}$ \\
\hline VSV-N(R7A) & $\begin{array}{l}-\mathrm{ss} \text { RNA } \\
12 \mathrm{~kb}\end{array}$ & A & Medium & $10-15$ & High & Low & $\mathrm{N}$ \\
\hline HSV H129 & $\begin{array}{l}\text { ds DNA } \\
153 \mathrm{~kb}\end{array}$ & $A / R$ & High & $3-5$ & Medium & Medium & Y \\
\hline HSV H8 & $\begin{array}{l}\text { ds DNA } \\
153 \mathrm{~kb}\end{array}$ & $A / R$ & High & $3-5$ & High & Medium & Y \\
\hline
\end{tabular}

Abbreviations: -ss RNA Negative-strand, single strand RNA, ds DNA Double strand DNA, Dir Direction of transsynaptic tracing, "A" Anterograde, "R" Retrograde, "N" Can't be used as a cre/flp dependent anterograde trans-multisynaptic viral tracer, " $Y$ " Can be used as a cre/flp dependent anterograde trans-multisynaptic viral tracer. VSV is a negative-stranded RNA virus, HSV is a double stranded DNA virus, there are many different characteristics between them, including genome, toxicity and application, etc. Researchers should choose the virus according to different experimental needs

further ameliorate the speed of toxicity by using VSV mutants and variants. Because the $M$ protein is one of the main components of VSV's rapid cytotoxicity by blocking host transcription and RNA export, $M$ mutants (M51R and $\triangle$ M51) have been chose as good candidates to delay toxicity [54-56]. We have developed one such VSV with $\mathrm{N}_{\mathrm{R} 7 \mathrm{~A}}$ and $\triangle$ M51 mutant, VSV-N $\mathrm{N}_{\mathrm{RA}}{ }^{-} \mathrm{M} 51$, and are in the process of evaluating the cytotoxicity and transmission features in vivo.

In summary, our findings suggest that Mutant-VSV $\left(\mathrm{VSV}-\mathrm{N}_{\mathrm{R} 7 \mathrm{~A}}\right)$ can be used as an efficient anterograde trans-multi-synaptic tracer, with attenuated cytotoxicity, and delayed but enhanced anterograde trans-synaptic spreading. The work can provide a promising anterograde tracer that enables researchers to explore more downstream connections of a given brain region, and observe the anatomical structure and the function of the downstream circuits over a longer time window.

\section{Abbreviations \\ VSV: Vesicular stomatitis virus; MOI: Multiplicity of infection; \\ DMEM: DULBECCO'S minimum essential media; PBS: Phosphate buffer saline; DAPI: 4',6-diamidino-2-phenylindole; DG: Dentate gyrus; VTA: Ventral tegmental area; AON: Anterior olfactory nucleus; TTd: Taenia tecta, dorsal part; TTv: Taenia tecta, ventral part; LS: Lateral septal nucleus; ACB: Nucleus accumbens; NDB: Diagonal band nucleus; OT: Olfactory tubercle; \\ CP: Caudoputamen; SS: Somatosensory areas; MPN: Medial preoptic nucleus; BST: Bed nuclei of the stria terminalis; GPe: Globus pallidus, external segment; SI: Substantia innominata; FS: Fundus of striatum; MA: Magnocellular nucleus; AAA: Anterior amygdalar area; Habenula: Habenula; AHN: Anterior hypothalamic nucleus; CEA: Central amygdalar nucleus; BMAa: Basomedial amygdalar nucleus, anterior part; Al: Agranular insular area; PH: Posterior hypothalamic nucleus; DMH: Dorsomedial nucleus of the hypothalamus; PF: Parafascicular nucleus; RSP: Retrosplenial area; TEa: Temporal association areas; PIR: Piriform area; CA3: Ammon's horn Field CA3; DR: Dorsal nucleus raphe; PAG: Periaqueductal gray; CS: Superior central nucleus raphe; HY: Hypothalamus; vHPC: ventral hippocampus; BLA: Basolateral amygdalar nucleus; PFC: Prefrontal cortex; ACA: Anterior cingulate area; \\ MO: Somatomotor areas; SC: Superior colliculus; SOC: Superior olivary complex}

\section{Acknowledgements}

We thank Lingling Xu from Wuhan Institute of Physics and Mathematics for teaching and guiding confocal imaging.

\section{Authors' contributions}

$\mathrm{KL}, \mathrm{XH}$ and $\mathrm{FX}$ contributed to the study idea and design; $\mathrm{FX}$ and $\mathrm{XH}$ contributed to funding acquisition and resources; KL, XZ (Xin Zhong), MY, LL and ST performed the experiments and data acquisition; KL, XZ (Xin Zhong), MY, XZ (Xutao Zhu) and FX accomplished data analysis; KL and FX drafted the manuscript, and contributed to review and editing. All authors read and approved the final manuscript.

\section{Funding}

This work was supported by the Strategic Priority Research Program of the Chinese Academy of Sciences (XDB32030200), the Research and

Development Program in Key Areas of Guangdong Province

(2018B030331001), the Major Research Plan of the National Natural Science Foundation of China $(91632303,31671120)$, and the National Basic Research Development Program (973 Program) of China (2015CB755601).

\section{Availability of data and materials}

The datasets used or analysed during the current study are available from the corresponding author on reasonable request.

\section{Ethics approval and consent to participate}

All procedures used were approved by the Animal Care and Use Committees at the Wuhan Institute of Physics and Mathematics, Chinese Academy of Sciences. All the experiments with viruses were performed in Biosafety Level 2 laboratory and animal facilities. Consent to participate: Not applicable.

\section{Consent for publication}

Not applicable.

\section{Competing interests}

The authors declare that they have no competing interests.

\section{Author details}

${ }^{1}$ Wuhan National Laboratory for Optoelectronics, Huazhong University of Science and Technology, Wuhan 430074, China. ${ }^{2}$ Center for Brain Science, State Key Laboratory of Magnetic Resonance and Atomic and Molecular Physics, Key Laboratory of Magnetic Resonance in Biological Systems, Wuhan Center for Magnetic Resonance, Wuhan Institute of Physics and Mathematics, Innovation Academy for Precision Measurement Science and Technology, Chinese Academy of Sciences, Wuhan 430071, China. ${ }^{3}$ University of Chinese Academy of Sciences, Beijing 100049, PR China. ${ }^{4}$ Shenzhen Key Lab of Neuropsychiatric Modulation, Guangdong Provincial Key Laboratory of Brain Connectome and Behavior, CAS Key Laboratory of Brain Connectome and Manipulation, The Brain Cognition and Brain Disease Institute (BCBDI), Shenzhen Institutes of Advanced Technology, Chinese Academy of Sciences, Shenzhen, China. ${ }^{5}$ Shenzhen-Hong Kong Institute of Brain Science-Shenzhen Fundamental Research Institutions, Shenzhen 518055, China. ${ }^{6}$ Center for Excellence in Brain Science and Intelligence Technology, Chinese Academy of Sciences, Shanghai 200031, China. 
Received: 16 January 2020 Accepted: 12 March 2020

Published online: 20 March 2020

\section{References}

1. Crick F, Jones E. BACKWARDNESS OF HUMAN NEUROANATOMY. Nature. 1993;361(6408):109-10.

2. Insel TR. Rethinking schizophrenia. Nature. 2010;468(7321):187-93.

3. Smith BN, Banfield BW, Smeraski CA, Wilcox CL, Dudek FE, Enquist LW, et al. Pseudorabies virus expressing enhanced green fluorescent protein: a tool for in vitro electrophysiological analysis of transsynaptically labeled neurons in identified central nervous system circuits. Proc Natl Acad Sci U S A. 2000:97(16):9264-9.

4. Wickersham IR, Finke S, Conzelmann KK, Callaway EM. Retrograde neuronal tracing with a deletion-mutant rabies virus. Nat Methods. 2007:4(1):47-9.

5. Callaway EM, Luo L. Monosynaptic circuit tracing with glycoprotein-deleted rabies viruses. J Neurosci. 2015:35(24):8979-85.

6. Ciabatti E, Gonzalez-Rueda A, Mariotti L, Morgese F, Tripodi M. Life-long genetic and functional access to neural circuits using self-inactivating rabies virus. Cell. 2017;170(2):382-92 e14

7. Beier KT, Saunders A, Oldenburg IA, Miyamichi K, Akhtar N, Luo LQ, et al. Anterograde or retrograde transsynaptic labeling of CNS neurons with vesicular stomatitis virus vectors. Proc Natl Acad Sci U S A. 2011;108(37):15414-9.

8. Lo LC, Anderson DJ. A Cre-dependent, anterograde Transsynaptic viral tracer for mapping output pathways of genetically marked neurons Neuron. 2011;72(6):938-50.

9. Beier KT, Borghuis BG, El-Danaf RN, Huberman AD, Demb JB, Cepko CL. Transsynaptic tracing with vesicular stomatitis virus reveals novel retinal circuitry. J Neurosci. 2013;33(1):35-51.

10. Zeng WB, Jiang HF, Gang YD, Song YG, Shen ZZ, Yang $H$, et al. Anterograde monosynaptic transneuronal tracers derived from herpes simplex virus 1 strain H129. Mol Neurodegener. 2017;12(1):38.

11. Zheng N, Su P, Liu Y, Wang H, Nie B, Fang $X$, et al. Detection of neural connections with ex vivo MRI using a ferritin-encoding trans-synaptic virus. Neuroimage. 2019;197:133-42.

12. Wickersham IR, Lyon DC, Barnard RJ, Mori T, Finke S, Conzelmann KK, et al Monosynaptic restriction of transsynaptic tracing from single, genetically targeted neurons. Neuron. 2007;53(5):639-47.

13. Reardon TR, Murray AJ, Turi GF, Wirblich C, Croce KR, Schnell MJ, et al. Rabies virus CVS-N2C(DeltaG) strain enhances retrograde synaptic transfer and neuronal viability. Neuron. 2016;89(4):711-24.

14. Sun L, Tang Y, Yan K, Yu J, Zou Y, Xu W, et al. Differences in neurotropism and neurotoxicity among retrograde viral tracers. Mol Neurodegener. 2019:14(1):8.

15. Jia F, Lv P, Miao H, Shi XW, Mei HJ, Li L, et al. Optimization of the fluorescent protein expression level based on Pseudorabies virus Bartha strain for neural circuit tracing. Front Neuroanat. 2019:13:63.

16. Chatterjee S, Sullivan HA, MacLennan BJ, Xu R, Hou Y, Lavin TK, et al. Nontoxic, double-deletion-mutant rabies viral vectors for retrograde targeting of projection neurons. Nat Neurosci. 2018;21(4):638-46.

17. Sun N, Cassell MD, Perlman S. Anterograde, transneuronal transport of herpes simplex virus type 1 strain $\mathrm{H} 129$ in the murine visual system. J Virol. 1996;70(8):5405-13.

18. Beier KT, Mundell NA, Pan YA, Cepko CL. Anterograde or Retrograde Transsynaptic Circuit Tracing in Vertebrates with Vesicular Stomatitis Virus Vectors. Curr Protoc Neurosci. 2016:74:1.26.1-27.

19. van den Pol AN, Ozduman K, Wollmann G, Ho WS, Simon I, Yao Y, et al. Viral strategies for studying the brain, including a replication-restricted selfamplifying delta-G vesicular stomatis virus that rapidly expresses transgenes in brain and can generate a multicolor golgi-like expression. J Comp Neurol. 2009;516(6):456-81.

20. Mundell NA, Beier KT, Pan YA, Lapan SW, Goz Ayturk D, Berezovskii VK, et al. Vesicular stomatitis virus enables gene transfer and transsynaptic tracing in a wide range of organisms. J Comp Neurol. 2015;523(11):1639-63.

21. Beier KT, Saunders AB, Oldenburg IA, Sabatini BL, Cepko CL. Vesicular stomatitis virus with the rabies virus glycoprotein directs retrograde transsynaptic transport among neurons in vivo. Front Neural Circuits. 2013;7:11.

22. Hastie E, Cataldi M, Marriott I, Grdzelishvili VZ. Understanding and altering cell tropism of vesicular stomatitis virus. Virus Res. 2013;176(1-2):16-32.

23. Li J, Liu T, Dong Y, Kondoh K, Lu Z. Trans-synaptic neural circuit-tracing with neurotropic viruses. Neurosci Bull. 2019;35(5):909-20.

24. Harouaka D, Wertz GW. Second-site mutations selected in transcriptional regulatory sequences compensate for engineered mutations in the vesicular stomatitis virus nucleocapsid protein. J Virol. 2012;86(20):11266-75.
25. Chen L, Yan Q, Lu G, Hu Z, Zhang G, Zhang S, et al. Several residues within the $\mathrm{N}$-terminal arm of vesicular stomatitis virus nucleoprotein play a critical role in protecting viral RNA from nuclease digestion. Virology. 2015;478:9-17.

26. Chen $L$, Zhong $Y$, Hu Z, Oin $Y$, Chen M. Two second-site mutations compensate the engineered mutation of R7A in vesicular stomatitis virus nucleocapsid protein. Virus Res. 2016;214:59-64.

27. Chen $L$, Zhou $Y$, Zhao $M$, Chen $H$. R7A mutation in $N$ protein renders temperature sensitive phenotype of VSV by affecting its replication and transcription in vitro. Virus Genes. 2019:55(4):513-9.

28. Whelan SPJ, Ball LA, Barr JN, Wertz GTW. Efficient recovery of infectious vesicular stomatitis virus entirely from cDNA clones. Proc Natl Acad Sci U S A. 1995;92(18):8388-92.

29. Zhu X, Lin K, Liu Q, Yue X, Mi H, Huang X, et al. Rabies virus Pseudotyped with CVS-N2C glycoprotein as a powerful tool for retrograde neuronal network tracing. Neurosci Bull. 2019.

30. Flanagan EB, Schoeb TR, Wertz GW. Vesicular stomatitis viruses with rearranged genomes have altered invasiveness and neuropathogenesis in mice. J Virol. 2003;77(10):5740-8.

31. Novella IS, Ball LA, Wertz GW. Fitness analyses of vesicular stomatitis strains with rearranged genomes reveal replicative disadvantages. J Virol. 2004; 78(18):9837-41.

32. Harouaka D, Wertz GW. Mutations in the C-terminal loop of the nucleocapsid protein affect vesicular stomatitis virus RNA replication and transcription differentially. J Virol. 2009;83(22):11429-39.

33. Kim GN, Kang CY. Matrix protein of VSV New Jersey serotype containing methionine to arginine substitutions at positions 48 and 51 allows nearnormal host cell gene expression. Virology. 2007:357(1):41-53.

34. Fang X, Zhang S, Sun X, Li J, Sun T. Evaluation of attenuated VSVs with mutated M or/and G proteins as vaccine vectors. Vaccine. 2012;30(7):1313-21.

35. Chivero ET, Guo ML, Periyasamy P, Liao K, Callen SE, Buch S. HIV-1 tat primes and activates microglial NLRP3 Inflammasome-mediated Neuroinflammation. J Neurosci. 2017:37(13):3599-609.

36. Tanabe S, Uezono S, Tsuge H, Fujiwara M, Miwa M, Kato S, et al. A note on retrograde gene transfer efficiency and inflammatory response of lentiviral vectors pseudotyped with FuG-E vs. FuG-B2 glycoproteins. Sci Rep. 2019;9(1):3567.

37. Zheng Y, Feng S, Zhu X, Jiang W, Wen P, Ye F, et al. Different subgroups of cholinergic neurons in the basal forebrain are distinctly innervated by the olfactory regions and activated differentially in olfactory memory retrieval. Front Neural Circuits. 2018;12:99.

38. Morales M, Margolis EB. Ventral tegmental area: cellular heterogeneity, connectivity and behaviour. Nat Rev Neurosci. 2017;18(2):73-85.

39. Mahler SV, Brodnik ZD, Cox BM, Buchta WC, Bentzley BS, Quintanilla J, et al. Chemogenetic manipulations of ventral tegmental area dopamine neurons reveal multifaceted roles in cocaine abuse. J Neurosci. 2019;39(3):503-518.

40. Ikemoto S. Dopamine reward circuitry: two projection systems from the ventral midbrain to the nucleus accumbens-olfactory tubercle complex. Brain Res Rev. 2007:56(1):27-78.

41. Albanese A, Minciacchi D. Organization of the ascending projections from the ventral tegmental area: a multiple fluorescent retrograde tracer study in the rat. J Comp Neurol. 1983;216(4):406-20.

42. Tu Y, Bi Y, Zhang L, Wei H, Hu L. Mesocorticolimbic pathways encode Cuebased expectancy effects on pain. J Neurosci. 2020;40(2):382-94.

43. Lutas A, Kucukdereli H, Alturkistani O, Carty C, Sugden AU, Fernando K, et al. State-specific gating of salient cues by midbrain dopaminergic input to basal amygdala. Nat Neurosci. 2019:22(11):1820-33.

44. Taylor SR, Badurek S, Dileone RJ, Nashmi R, Minichiello L, Picciotto MR. GABAergic and glutamatergic efferents of the mouse ventral tegmental area. J Comp Neurol. 2014;522(14):3308-34.

45. Hosp JA, Pekanovic A, Rioult-Pedotti MS, Luft AR. Dopaminergic projections from midbrain to primary motor cortex mediate motor skill learning. J Neurosci. 2011;31(7):2481-7.

46. Zhang Z, Liu Q, Wen P, Zhang J, Rao X, Zhou Z, et al. Activation of the dopaminergic pathway from VTA to the medial olfactory tubercle generates odor-preference and reward. Elife. 2017:6:e25423.

47. Ugolini G. Advances in viral transneuronal tracing. J Neurosci Methods. 2010;194(1):2-20

48. Su P, Ying M, Han Z, Xia J, Jin S, Li Y, et al. High-brightness anterograde transneuronal HSV1 H129 tracer modified using a Trojan horse-like strategy. Mol Brain. 2020;13(1):5

49. David RM, Doherty AT. Viral vectors: the road to reducing Genotoxicity. Toxicol Sci. 2017;155(2):315-25. 
50. Liddelow SA, Guttenplan KA, Clarke LE, Bennett FC, Bohlen CJ, Schirmer L, et al. Neurotoxic reactive astrocytes are induced by activated microglia. Nature. 2017;541(7638):481-7.

51. Green TJ, Zhang X, Wertz GW, Luo M. Structure of the vesicular stomatitis virus nucleoprotein-RNA complex. Science. 2006;313(5785):357-60.

52. Nassi JJ, Cepko CL, Born RT, Beier KT. Neuroanatomy goes viral! Front Neuroanat. 2015;9:80

53. Ohara S, Sota Y, Sato S, Tsutsui KI, lijima T. Increased transgene expression level of rabies virus vector for transsynaptic tracing. PLoS One. 2017;12(7):e0180960.

54. Stojdl DF, Lichty BD, Paterson JM, Power AT, Knowles S, Marius R, et al. VSV strains with defects in their ability to shutdown innate immunity are potent systemic anti-cancer agents. Cancer Cell. 2003;4(4):263-75.

55. Ahmed M, Cramer SD, Lyles DS. Sensitivity of prostate tumors to wild type and M protein mutant vesicular stomatitis viruses. Virology. 2004;330(1):34-49.

56. Ayala-Breton C, Suksanpaisan L, Mader EK, Russell SJ, Peng K-W. Amalgamating oncolytic viruses to enhance their safety, consolidate their killing mechanisms, and accelerate their spread. Mol Ther. 2013;21(10):1930-7.

\section{Publisher's Note}

Springer Nature remains neutral with regard to jurisdictional claims in published maps and institutional affiliations.

Ready to submit your research? Choose BMC and benefit from:

- fast, convenient online submission

- thorough peer review by experienced researchers in your field

- rapid publication on acceptance

- support for research data, including large and complex data types

- gold Open Access which fosters wider collaboration and increased citations

- maximum visibility for your research: over $100 \mathrm{M}$ website views per year

At BMC, research is always in progress.

Learn more biomedcentral.com/submissions 